\title{
Specific Features in Management of Agro-Food System Development
}

\author{
Kovalenko Yu.N.* \\ Basic Department of Financial Control, Analysis and audit \\ Main Control Department of the city of Moscow \\ Plekhanov Russian University of Economics \\ Moscow, Russia \\ yuliya.severina@gmail.com
}

\begin{abstract}
Management of the development of socioeconomic systems should be reasonably considered as control of the processes of their changes. The management of the processes of quantitative and qualitative changes has a pronounced adaptive orientation, while the objects of various adaptation adjustments are traditionally the set of goals, the content of the system's functionality, its structural construction, and economic boundaries. The complexity of the structure of the agro-food complex and the heterogeneity of its structural elements complicate the functionality of the management system for this type of territorial-sectoral entities and require the formation and use of a specific development management mechanism. The goal of managing structural changes in agro-food systems is to create the optimal structure and maintain proportions between the structural elements that maximize the efficiency of agriculture through state regulation of the development processes of territorial-industrial complexes, the impact on the product orientation of large, medium, and small businesses, the development of infrastructure support system, and intensification of innovation in agro-food complex. It is proposed to use models of balanced development as a tool for designing a development strategy for regional agro-food complexes, which are a formalized description of conceptual provisions that determine the evolution of agro-economic systems and reflect the state's position as the natural macro-regulator.
\end{abstract}

Keywords - development, management, agro-food system, agro-food complex, control mechanism.

\section{INTRODUCTION}

Management of the development of socio-economic systems should be reasonably considered as control of the processes of their changes. This is primarily due to the need to manage structural changes aimed at maintaining optimal proportions between the structural elements of the system, allowing the fullest possible use of the development potential of territorial-sectoral complexes due to the redistribution of resources between individual sectors and territories, the impact on the adjustment of the production direction of economic entities of various levels, modernization of the infrastructure support system for local territories, the formation of the conditions for the transition to the innovation-oriented development model that determines the direction and intensity of structural changes in accordance with the changing paradigm of social development.

\author{
Ulez'ko A.V. \\ Chair of Information support and modeling of economic \\ systems in agriculture \\ Voronezh State Agrarian University \\ Voronezh, Russia \\ arle187@rambler.ru
}

In the recent economic literature, change management, as a rule, is considered in the context of managing business entities at various levels [1-5] and is limited to studying the issues of their adaptation to natural changes in the functioning environment through the modernization of the management system of individual business processes. But if the availability of effective tools for change management in economic entities is considered to be an objectively necessary component of the management mechanism, then with regard to meso- and macro-level systems, problems of change management are considered relatively seldom, whereas without clear understanding of the need for the purpose of changes, their direction, depth and degree of intensity, it seems virtually impossible to effectively manage the development of complex socio-economic systems.

If we consider that the evolution of socio-economic systems proceeds on the basis of the principles of selfdevelopment and self-organization, it becomes obvious that the management of quantitative and qualitative changes has a clearly defined adaptation focus, and the objects of various adaptation adjustments are traditionally the set of goals, the content of the system's functional, its structural construction, and economic boundaries. It should be noted that it is the adjustment of the structure of the economic system that seems to be one of the most available and effective adaptation tools that ensure its adaptation to objectively occurring changes in the external environment and allow overcoming various kinds of imbalances and smoothing out objectively existing contradictions related to the mismatch of interests of subjects of the intra-system interactions. If we assume the invariance of the global development goals of a particular socio-economic system at a specific stage of its evolution, then it can be argued that in the aggregate of system changes that provide the possibility of achieving the goals, structural changes should occupy the most important place.

\section{RESEARCH RESULTS}

The objective nature of the continuous structural changes in agro-food complexes as socio-economic systems in the course of their evolutionary development is explained by the need for:

- adequate response to the evolutionary changes of the systems themselves associated with the adjustment of local development goals and objectives, functions, boundaries, and individual parameters; 
- maintaining the ability of systems to satisfy the economic interests of their constituent entities and to balance their interests in order to overcome internal contradictions and minimize their effect;

- constant adaptation to changes in the volume and structure of social needs, taking into account trends in the development of the agricultural market and changes in the competitive environment;

- maintaining the optimal development path that creates the conditions for achieving strategic development goals while ensuring the minimum level of investment and operational costs;

- the most effective use of mechanisms of state regulation and state support for the development of individual industries and territorial entities that form agro-food complexes of various levels.

The complexity of the structure of the agro-food complex and the heterogeneity of its structural elements in terms of level and pace of development significantly complicate the functionality of the management system for this type of territorial-sectoral entities and require the formation and use of a specific development management mechanism that implements the goal-setting, strategic nature of changes, substantiation of directions and depth of the required structural changes, initiation and motivation of changes, coordination of their processes and activities of agro-food complex entities implementing the program of strategic changes, the formation of the conditions that ensure the resolution of objective contradictions between the agro-food complex entities, as well as between the reproductive potential of territorial-sectoral entities and growing social needs [6-10].

The key tool for smoothing out these contradictions is the management of the processes of distribution and redistribution of economic resources between the structural elements of the agro-food complex, which are the objects of management of the system of agricultural production and rural development

The tasks of development management are to create the conditions necessary to achieve the goals of the system's development, adapt the system to changes in its operational environment, maintain the optimal structure of the system, and keep the system on the optimal development path.

The sectors of the agro-food complex, territorial formations, business entities of all categories, production and market infrastructure, subsystems of scientific and personnel support, and intra-system communications are defined as the objects of managerial influence.

The basic principles of managing the development of the agro-food complex include the principles of consistency, balance, efficiency, optimality, adaptability, resource support, justice, and social orientation.

Under the current conditions, the quality of the competitive and institutional environment can be considered as the key factor determining the vector of structural changes and defining the depth of structural changes. The basic institution that affects the level of development of the competitive environment and forms the conditions for the provision of preferences for certain economic agents is considered to be the state that implements the functions of the macro-regulator of economic processes in the framework of the use of such tools as budget, credit, tax, antitrust, agrarian, and other policies, state target programs and other means of direct influence on the creation of equal conditions for access of all subjects of the agricultural sector to resources and factors of production, barrier-free access to markets of the goods produced and so forth. It is the state that should play the role of the natural initiator of processes of changes in the structure of the systems it controls, supporting the development of specific sectors and territories, demonstrating its strategic plans for the development of certain forms of agribusiness.

The goal of the management of structural changes in agrofood systems is to create the optimal structure and maintain proportions between the structural elements that maximize the efficiency of agriculture through state regulation of the development processes of territorial-sectoral complexes, the impact on the product orientation of large, medium, and small businesses, the development of infrastructure support system, intensifying innovation in agro-food complex.

The scale and duration of the processes of initiation and occurrence of structural changes objectively determine the need for their relevance to the competence of strategic management of the development of territorial-sectoral entities.

The agro-food complex as an agro-food system is a specific multi-level and complexly structured management object that reasonably requires a rational combination of sectoral and territorial development strategies [11-16]. The modern model of development of the agrarian economy and rural territories, which was formed in the course of the radical economic reforms, is in deep contradiction with the fundamental interests and needs of a significant part of the rural population and agricultural producers. Its contradictory nature provokes the growth of the bundle of socio-economic problems of the countryside, which include: deformation of its demographic structure, increased outflow of economically active rural population, low rates of diversification of the rural economy, compression of healthcare and education infrastructure, critically low level of budget filling of rural settlements and municipalities, etc. The high level of depression of the rural economy and rural communities in certain regions of the country threatens the effective use of the potential of rural areas of Russia and the preservation of social control over them, and also causes a self-reproducing decline in the living standards of a significant part of the rural population.

The issues of resolving the contradictions of the processes of rural development are becoming especially relevant in the conditions when the society and the state are facing global challenges due to the need for the country and its agro-food complex to switch to the innovation-oriented development path. In this regard, the agro-food complex development strategy should be focused on increasing the efficiency of using the rural development potential of individual localized territories, mitigating the contradictions that exist between the subjects of agrarian relations, and balancing their economic 
interests. That means that along with the state strategy for the agro-food complex development, strategies for the development of regional-sectoral systems at the regional level should be formed.

The creation of the strategies for the development of agrofood complexes at the regional level involves the achievement of such tasks as:

- substantiation of the theoretical and methodological aspects of balanced rural development processes, reflecting its structure and content, as well as the specifics of the existing and perspective models of territorial and sectoral development;

- the study of the current issues of the agricultural economy development, the identification of patterns, trends, and interconnections of the development of the agricultural sector and rural areas, as well as the system of contradictions arising from the inconsistency of strategies for sectoral and territorial development;

- classification of territorial entities taking into account the existing agrarian structure, levels of development of agricultural production and rural territories;

- development of methodological and instrumental support for the study of the processes of territorialsectoral development of agro-food systems based on the use of a complex of statistical, simulation, and optimization models;

- substantiation of the promising development parameters of regional agro-food complexes based on the use of standardized models of territorial and sectoral development.

The proposed conceptual approach to developing a strategy for the development of agro-food complexes of various levels provides for:

- revealing the composition, structure, and functions of the agro-food complex development management system and substantiating the directions for its improvement;

- assessment of patterns and trends in the structure of the agricultural sector of territorial entities and the interconnections of the development of agricultural production and rural territories;

- actualization of the set of tasks for the development of the agro-food complex in the medium and long term, taking into account the differentiation of territorial entities by the level of economic development;

- building theoretical and empirical models for the integrated development of agro-economic systems of various levels;

- the development of a mechanism for coordinating the interests of subjects of agrarian relations in the framework of managing the processes of the territorial and sectoral development;
- creation of the standard models for balanced territorial and sectoral development of regional agro-food complexes;

- designing a set of statistical, simulation, and optimization models to substantiate the forecast parameters for balancing the development of regional agro-food complexes.

It is proposed to use the models of balanced territorial and sectoral development as a tool for developing the strategy for the development of regional agro-food complexes, which are a formalized description of conceptual provisions that determine the evolution of agro-economic systems at the regional level, differentiated by the structure of the agrarian sector and the level of development of agriculture and rural territories, in conditions of the growth of the social responsibility of agribusiness, as well as reflecting the position of the state as the natural macro-regulator in the process control system for rural development and to assess the economic and social implications of the alternative scenarios for the development of agro-economic systems. The use of these models will allow not only to develop forecasts for the development for regional agro-food complexes, but to justify mechanisms for reconciling the economic interests of the subjects of the territorial and sectoral development, to describe its structure and functionality, the system of indicators formalizing global and local development goals of regional agro-economic systems, the set of methods and tools used to create the required conditions for effective development, as well as to form the information basis for the prediction of the trajectories ensuring the achievement of the goals.

Summarizing and systematizing the approaches that have been formed in the Russian economic literature to understanding the prospects and opportunities for the development of rural territories as a natural element of the agro-food complex as a territorial-sectoral formation [], it is proposed to single out the priority areas: development of the agricultural production system, diversification of the rural economy, development of infrastructure support, social, environmental, and organizational-economic development.

As a part of the development of the agricultural production system, it is proposed to give priority to adjusting the structure of the agricultural sector in order to ensure the optimal combination of large, medium, and small businesses and modernizing the technical and technological base of agriculture. The same block presents measures related to the involvement of unused productive lands in the economic turnover, increasing the number of livestock and poultry and their genetic potential, and increasing the productive potential of crops.

As a part of the diversification of the rural economy, it is assumed that the territorial systems are oriented towards the development of processing and other industrial sectors, the development of the service markets, consumer cooperation, and rural tourism in accordance with the specifics of the development potential of certain territories.

In addition, the priority should be given to the development of industrial, social, engineering, transport and logistics, market, and information infrastructures. 
In the context of the social development of rural areas, special attention should be paid to the issues related to the stabilization of demographic processes in rural areas, the growth of the levels of employment and self-employment of villagers and their income, the improvement of the living standards, the volume of investments in human capital, the effectiveness of local self-government and public activity of rural communities.

Recently, with the increase in the intensification of agricultural production and the level of anthropogenic pressure, environmental problems began to worsen. In the framework of environmental development, the priority can be placed on the measures related to the formation of sustainable ecosystems, the transition to ecological-landscape systems of farming, ensuring the environmental safety of manufactured products, the use of organic farming technologies, and the conservation of the biological diversity of territories.

The implementation of the above directions is possible only if the activities take place related to the development of the public-private partnership system, the effective integration of rural territories into a single economic space, increase of their investment attractiveness, creation of the conditions for the development of small business, and increase of the entrepreneurial activity of the rural population.

It should be recognized that the sustainable and effective development of the agro-food complex is possible only within the framework of the implementation of complex models of territorial and sectoral development at various levels, ensuring the coordination of interests of business representatives and rural communities.

It is in this connection that balancing the strategic interests of business structures and rural areas is one of the global and one of the most difficult tasks facing the governing bodies of the regional agro-food complex. Currently, this problem can be considered unsolved, which allows concluding that the regional rural development policy is not effective enough.

It is possible to achieve increased efficiency of publicprivate partnerships and its harmonious integration in the context of the development strategy for the agro-food complex, if the following conditions are fulfilled:

- paradigm shift in public administration of the agrofood complex as a territorial and sectoral entity and increase of the social responsibility of business;

- selection of rational methods and instruments of state influence on the course of economic processes that ensure the realization of the interests of territorial entities and agricultural producers of all types;

- the use of innovative forms of state influence on large business structures through the implementation of a cluster model for the development of the agro-food complex, the change in the forms of interaction of the state with large integrated agro-industrial formations of the national and inter-regional levels, etc.

Obviously, the initiation and implementation of the largescale structural changes is possible only if there are adequate financial support mechanisms and appropriate amounts of financial resources that can be distributed among the entities that form the system in accordance with its development strategy. It should also be borne in mind that the transformation of the structure of the system, which provides the generation of positive transformational effects, is mainly associated with the modernization of the technical and technological base of the production system, implemented as a set of investment projects. That means that the investment resources acquire the status of the key resources and become an effective tool for regulating the processes of structural changes in the system of the public production.

The following provisions can be identified as the basic provisions defining the ideology of developing investment support for the development of the agro-food complex:

- the state investment policy in relation to the agro-food complex should be formed on the basis of its development strategy, taking into account the longterm prospects for the development of agriculture, food and processing industries, and rural areas;

- limited amount of investment resources should be allocated based on their public interests, not the interests of individual business structures;

- state support should be provided only to those investment projects that are economically or socially significant for specific local territories;

- when allocating public support funds, the state should give priority to investment projects that ensure the maximum multiplier effect;

- the state must guarantee equal access to investment resources to all subjects of large, medium, and small agribusiness in order to ensure the maximum possible level of use of the agricultural potential of local territories;

- the cost of investment resources should ensure the competitiveness of the economic benefits produced as a result of the implementation of the investment projects, and the totality of the effects obtained should exceed the level of investment and operating costs for the estimated payback period of the project

- the government should offer business some effective investment risk management mechanisms minimizing possible losses in the situation of high environmental turbulence;

- implementation of large-scale investment projects should be carried out on the principles of public-private partnership with increasing responsibility of business structures for the efficient use of state support funds;

- in the situation of limited financial capabilities of a significant part of economic entities of the agrarian sector, the state needs to develop the mechanisms to stimulate their investment activity, etc.

In the context of the state's orientation to the priority support of large-scale production, there is an increase in the 
imbalance of agro-food systems, associated not only with the growing concentration of agricultural capital and the sharp reduction in the number of jobs in the countryside, but also with the growth in their influence on the distribution processes of the limited amount of state support funds, pressure on small businesses in those niches where they remained competitive (for example, in pig breeding), with an increase in environmental problem resulting from increasing the intensity level of the land use and the high concentration of livestock farm animals and poultry.

The main functions of the managing mechanism for the development of agro-food systems shall be:

- substantiation of the target parameters for the development of the management object and its sectoral and territorial elements and the optimal development path ensuring the achievement of the set goals;

- substantiation of the direction and depth of the structural changes required for reaching the optimal development path;

- creation of an adequate system of infrastructural support for the processes of sectoral and territorial development of the management object, a favorable competitive environment and conditions for balanced development;

- continuous monitoring of the processes of the management object development, assessment of the effectiveness of the structural changes and the effective use of tools to adapt the management object to the changes in the environment of its functioning, etc.

\section{CONCLUSIONS}

The formation of the mechanism for balancing the interests of agribusiness entities and smoothing out the contradictions that intrinsically arise between them within the framework of the established model of inter-subject interactions is among the priority tasks of improving the agro-food complex management system. The main functions of this mechanism include: creation of the conditions for fair competition and prevention of the use of methods of unacceptable competitive behavior; provision of the equal access for all economic entities of the agro-food complex to resources and means of state support; elimination of administrative barriers for the free access of all types of economic agents to local markets; pursuing the active antitrust policy; maintenance of a certain level of profitability of agricultural production sectors; additional support for small business forms in order to ensure the conditions for the growth of self-employment of the rural population and their income level, etc.

\section{References}

[1] M. Laužikas, A. Miliute, "Communication efficiency and effectiveness within strategic management of change: insights into civil service organizations", J. of Security and Sustainability Issues, vol. 8, no. 4, pp. 617-630, 2019.

[2] M. Goubko, "Ooptimal organizational structures for change management in production", Intellig. Syst. Reference Library, vol. 98, pp. 59-83, 2016.

[3] M.A. Öner, S. Göl Beșer, C. Benson, "Linking organizational change management and organizational foresight", Strategic Change, vol. 23, no. 3-4, pp. 185-203, 2014.

[4] D.V. Zamuriy, T.A. Kostikova, V.G. Germanova, M.G. Podoprigora "Organizational change management methods", Modern Sci., no. 1-1, pp. 36-41, 2020.

[5] E. Setyanto, A. Ikhwan, S. Amin, U.M. Shabir, Suharto, "Challenges of the change management for managing people and organizational culture", Int. J. of Recent Technol. and Engineer., vol. 8, no. 2, spec. iss. 11, pp. 3822-3826, 2019.

[6] L. Kucher, M. Heldak, A. Orlenko, "Project management in organic agricultural production", Agricult. and Resource Econ.: Int. Sci. E-J., vol. 4, no. 3, pp. 104-128, 2018

[7] M. Shulskyi, "Forms of management in agricultural production: state and development opportunities", Agricult. and Resource Econ.: Int. Sci. E-J., vol. 3, no. 2, pp. 159-171, 2017.

[8] I. Lutsenko, "The system of the management of stable development of rural territories: comparison of the native and foreign experience", Eureka: Soc. and Human., vol. 6, no. 6, pp. 10-14, 2016.

[9] N. Ozeranskaya, R. Abeldina, G. Kurmanova, Z. Moldumarova, L. Smunyova, "Agricultural land management in the system of sustainable rural development in the Republic of Kazakhstan”, Int. J. of Civil Engineer. and Technol., vol. 9, no. 13, pp. 1500-1513, 2018.

[10] T.I. Bukhtiyarova, I.V. Hilinskaya, A.V. Ilyinykh, A.A. Tenetko, "The mechanism for implementing new forms of interaction and management of rural territories: economic and legal aspects", IOP Conf. Ser. Earth and Environmental Sci. conf. proc., p. 22007, 2020.

[11] V.P. Samarina, A.V. Samarin, T.P. Skufina, S.V. Baranov, "Russia's agro industrial complex: economic and political influence factors and state support", Smart Innovat., Syst. and Technol., vol. 138, pp. 579-593, 2020.

[12]. A. Ulezko, A. Tyutyunikov, A. Kurnosov, "Theoretical and methodological aspects of designing prospective models for agricultural development", IOP Conf. Ser. Earth and Environmental Sci., vol. 274, p. 012063, 2019.

[13] L. Smutka, M. Maitah, N. Ishchukova, "Russian rural population development in relation to agricultural sector transformation", Int. Busin. Manag., vol. 9, no. 4, pp. 492-497, 2015.

[14] K.V. Averkieva, A.I. Dan'shin, D.Yu. Zemlyanskii, S.V. Lamanov, "Strategic challenges of the development of agriculture in Russia", Reg. Res. of Russ., vol. 7, no. 4, pp. 322-332, 2017.

[15] Y. Kozenko, Z. Kozenko, A. Bobicheva, K. Kozenko, M. Filin, "Perspectives of development of agriculture in crisis by the example of present-day Russia”, Europ. Res. Studies J., vol. 19, no. 2, pp. 171-178, 2016.

[11] A.V. Bogoviz, "The new paradigm of innovational development of Russia's AIC in the conditions of the EAEU", Lecture Notes in Networks and Systems Growth Poles of the Global Economy: Emergence, Changes and Future Perspectives. Luxembourg: Plekhanov Russian University of Economics, 2020, pp. 193-202. 